\title{
NEgOCIACIÓN COLECTIVA RAMAL Y LOS MECANISMOS DE EXTENSIÓN: LOS CASOS DE ESPAÑA Y FRANCIA*
}

[Sectorial collective bargaining and the extension mechanisms: the cases of Spain and France]

\author{
Sergio Gamonal C.** \\ Universidad Adolfo Ibáñez \\ Pablo Arellano O.*** \\ Pontificia Universidad Católica de Valparaíso
}

\begin{abstract}
RESUMEN
Dentro de los modelos de negociación colectiva propuestos por Gino Giugni hay dos en los que el resultado de la negociación se encuentra sujeto a condiciones externas. Es por ello que se les denomina modelos intervenidos o reglados. En este trabajo estudiaremos dos ejemplos de estos modelos: España y Francia, desde la perspectiva del rol de la ley en sus procedimientos con miras a visualizar sus diferencias, virtudes $y$ defectos. A modo de conclusión, se intentará resaltar aspectos que a juicio de los autores resultan atingentes para el derecho colectivo chileno
\end{abstract}

\begin{abstract}
Within the collective bargaining models proposed by Gino Giugni there are two in which the outcome of the negotiation is subject to external conditions. That is why they are called intervened or regulated models. In this paper we will study two examples of these models: Spain and France, from the perspective of the role of the law in their procedures with a view to visualizing their differences, virtues and defects. As a conclusion, we will try to highlight aspects that according to the authors are pertinent to Chilean collective bargaining law.
\end{abstract}

*Este artículo forma parte del Proyecto Fondecyt Regular titulado "La negociación colectiva y su ámbito de cobertura más allá de la empresa”, N. ${ }^{\circ} 1170132$, en el que el Profesor Sergio Gamonal C. es el investigador principal.

** Licenciado en Ciencias Jurídicas y Sociales, Universidad de Chile. Profesor de Derecho del Trabajo, Universidad Adolfo Ibáñez, Chile. Dirección postal: Avda. Diagonal Las Torres 2640, of. 202-B, Peñalolén, Santiago. Correo electrónico: Sergio.gamonal@uai.cl.

*** Especialista en Derecho del Trabajo, Unidad de Derecho Laboral y Reforma, Departamento de Gobernanza y Tripartismo de la OIT, Ginebra, Suiza. Investigador, Facultad de Derecho, Pontificia Universidad Católica de Valparaíso, Chile. Las opiniones expresadas incumben solamente al autor y no representan necesariamente los puntos de vista de la Organización Internacional del Trabajo. Correo electrónico: arellano@ilo.org. 
Palabras Clave

Derecho del Trabajo - Negociación colectiva - Modelos intervenidos o reglados - Negociación ramal - Extensión - Ampliación - España - Francia.

\section{KEYWORDS}

Labor Law - Collective bargaining - Intervened or regulated models Branch or sector negotiation - Extension - Enlargement - Spain - France.

Recibido el 25 de octubre de 2018 y Aprobado el 27 de marzo de 2018

\section{INTRODUCCIÓN}

El derecho del trabajo se ha caracterizado por su desarrollo dual entre contrato de trabajo y contrato colectivo, el primero, como receptáculo de la protección estatal del trabajador por medio de la ley con derechos mínimos e inderogables ${ }^{1} \mathrm{y}$, el segundo, por medio de la denominada línea sindicalista de derecho laboral ${ }^{2}$, centrada básicamente en la actividad sindical (negociación colectiva y huelga) ${ }^{3}$.

La tutela individual se ha efectuado a través de la intervención legislativa y de la fiscalización hecha por los organismos inspectores contemplados en las distintas legislaciones. En la tutela individual, podemos hablar de una línea constitucional, basada en el garantismo individual protagonizado por la ley ${ }^{4}$.

La doctrina ha destacado que la denominada línea sindicalista por medio de la negociación colectiva y de los mecanismos de autotutela, equilibra de mejor forma las asimetrías de poder entre empleadores y trabajadores ${ }^{5}$.

Como señala Antonio Baylos: "La idea básica en la que se desemboca es, expuesta a grandes rasgos, la de tender hacia un sistema regulador de las relaciones laborales basado en la autonomía colectiva, en la discusión y el consenso (oposición-compromiso) libremente alcanzado y sostenido por los propios actores sociales, más que apuntalado en el formalismo contractual y en la coerción estatal" ${ }^{6}$. En este mismo sentido Guido

\footnotetext{
${ }^{1}$ Gamonal Contreras, Sergio, Las dos almas del derecho del trabajo, en Revista de Derecho Laboral y Seguridad Social 1 (2013), 1, pp. 13-22 y 14.

${ }^{2}$ GiUgNi, Gino Lavoro, legge, contratti (Bolonia, Il Mulino, 1989), p. 333.

${ }^{3}$ Gamonal Contreras, Sergio, Derecho Colectivo del Trabajo (2a edición revisada y actualizada, Santiago, Abeledo Perrot, 2011), pp. 9 ss.

${ }^{4}$ Giugni, cit. (n. 2), p. 333.

${ }^{5}$ D'Antona, Massimo, I mutamenti del diritto del lavoro ed il problema della subordinazione, en Caruso, Bruno - Sciarra, Silvana, OPERE (Milán, Giuffrè, 2000), III, pp. 1217-1218.

${ }^{6}$ Baylos Grau, Antonio, Derecho del Trabajo: modelo para armar (Madrid, Trotta, 1991), p. 39.
} 
Macchiavello ha enfatizado dentro de las características del derecho colectivo la "normatividad privada" que emana de los grupos colectivos que acuerdan normas que tienen fines propios de la $\mathrm{ley}^{7}$. En efecto, la normatividad en el derecho colectivo asume caracteres especiales debido a que emana de los actores sociales, a través de acuerdos colectivos, creando derecho objetivo en ciertos $\operatorname{casos}^{8}$.

De esta forma, la acción sindical conlleva el reconocimiento de la necesidad de los trabajadores de tener un contrapeso frente a la subordinación que tienen ante el empleador. Con la línea sindicalista o dimensión colectiva los trabajadores recuperan su libertad perdida en el contrato de trabajo?

La tutela colectiva o línea sindical incluso ha llegado a constituir un pilar del sistema democrático ${ }^{10}$.

Este artículo se centrará en los sistemas de negociación ramal y los mecanismos de extensión. Ambos sistemas (negociación ramal y mecanismos de extensión) comprenden diversas modalidades ${ }^{11}$, y en este trabajo ocuparemos la clásica taxonomía de Gino Giugni formulada hace varias décadas y que distingue entre ${ }^{12}$ :

i) Reconocimiento a los actores sociales del poder de dictar normas vinculantes para todos los sujetos incluidos en el ámbito del contrato, aunque no estén afiliados a los sindicatos respectivos.

ii) Casos en que el poder de extensión generalmente se atribuye al Gobierno o a la autoridad administrativa. Es decir, se distingue entre la estipulación del contrato colectivo y la atribución de eficacia del mismo.

iii) Recepción del contrato en una ley formal, o por la aplicación del mismo por los tribunales de justicia, o por la dictación por parte del Gobierno o de las autoridades administrativas de normas que recogen condiciones laborales mínimas para un sector determinado en base al contrato colectivo elegido como modelo.

${ }^{7}$ Macchiavello Contreras, Guido, Derecho Colectivo del Trabajo (Santiago, Editorial Jurídica de Chile, 1989), p. 35.

${ }^{8}$ Gamonal, cit. (n. 3), p. 27.

${ }^{9}$ Supiot, Alain, Crítica del Derecho del Trabajo (Madrid, Ministerio del Trabajo y Asuntos Sociales, 1996), p. 148.

${ }^{10}$ Baylos Grau, Antonio, ¿Para qué sirve un sindicato? (Madrid, Catarata, 2012), p. 22.

${ }^{11}$ Fita Ortega, Fernando, Los modelos de negociación colectiva en la Unión Europea, en RojAs, Irene (coord.), La Negociación Colectiva en Chile (Santiago, CENTRASS, Librotecnia, 2014), p. 17.

${ }^{12}$ Giugni, Gino, La extensión de los contratos colectivos, en ERmida, Óscar OjedA, Antonio, La Negociación Colectiva en América Latina (Madrid, Trotta, 1993), pp. 160 ss. 
iv) También puede haber una suerte de "aplicación espontánea" realizada por los actores sociales.

Los países con mayor cobertura negociadora han desarrollado algunas de estas modalidades descritas por Giugni. Por ejemplo, en los 16 países con mayor productividad laboral en la OCDE, en el año 2014, existe negociación colectiva ramal. En algunos es la forma predominante de negociar y en otros está presente sin ser dominante. Pero en 6 de los 7 más productivos predomina la negociación ramal ${ }^{13}$. Por otro lado, el promedio de la cobertura de la negociación en los países de Europa del Oeste es de alrededor del $70 \%{ }^{14}$ y, en los 28 países miembros de la Unión Europea más Noruega, el promedio es del 62\% de cobertura de la negociación colectiva ${ }^{15}$.

En el caso europeo, los países con mayor cobertura de negociación son aquellos con negociación ramal o algún mecanismo de extensión ${ }^{16}$. Un contraejemplo es Gran Bretaña, con negociación a nivel de empresa y una baja cobertura en comparación con otros países europeos ${ }^{17}$.

En este artículo nos centraremos en los casos español y francés, que son buenos ejemplos de la modalidad 1 de Giugni en el caso de España y de la modalidad 2 del mismo autor en el caso de Francia. Es decir, la legislación española es un buen ejemplo de reconocimiento a los actores sociales del poder de dictar normas vinculantes para todos los sujetos incluidos en el ámbito del contrato, y la francesa de un poder de extensión atribuido al Gobierno o a la autoridad administrativa. En ambos países encontramos la otra modalidad, es decir, extensión en España y normas vinculantes emanadas de los actores sociales en Francia, pero nuestro objetivo se enfoca en estudiar un ejemplo de cada modalidad y ver el rol del legislador en los procedimientos establecidos en cada una.

Ambos son modelos intervenidos o reglados, con protagonismo de

${ }^{13}$ Durán, Gonzalo, Negociación Colectiva por Sector Económico, Productividad, empleo y desigualdad. Un análisis comparado (Santiago, Fundación Sol, 2015).

${ }^{14}$ Disponible [en línea]: https://izajolp.springeropen.com/articles/10.1186/ s40173-016-0061-1 (visitada el 24 de julio de 2018).

15 Disponible [en línea]: http://www.worker-participation.eu/NationalIndustrial-Relations/Across-Europe/Collective-Bargaining2 (visitada el 24 de julio de 2018).

${ }^{16}$ Casanova, Javier Alexandre, Negociación Colectiva y Poder Sindical en Europa (Universidad Autónoma de Barcelona, 2013). Disponible [en línea]: https://www. researchgate.net/publication/237201862_NEGOCIACION_COLECTIVA_Y_ PODER_SINDICAL_EN_EUROPA,pp. 12 y 13 (visitada el 24 de julio de 2018).

${ }^{17}$ Casanova, cit. (n. 16), p. 13. 
la ley a diferencia de los modelos más autónomos, donde el sistema de relaciones laborales se basa en el rol protagónico de los actores sociales con relativa independencia del Estado, que se limita a establecer normas mínimas a fin de asegurar ciertos niveles de necesario cumplimiento y evitar excesos o abusos ${ }^{18}$, como es el caso de Uruguay ${ }^{19}$ e Italia ${ }^{20}$.

Revisando el modelo español y francés, desde la perspectiva del rol de la ley en los procedimientos, podremos visualizar sus diferencias, virtudes y defectos. Escapa al objetivo de este artículo una revisión completa y acabada de cada modelo o hacer un análisis comparativo de los mismos. Por el contrario y como ya hemos explicado, su pretensión es más sencilla en orden a dilucidar el rol de la legislación dentro de cada modelo.

En los últimos años, tanto en España (Rajoy) como en Francia (Macron), ha habido enmiendas al sistema de negociación colectiva de cada país orientadas a fortalecer la negociación y la descentralización a nivel de empresa. Aunque haremos referencias a dichos cambios, nuestro objetivo se centra, como ya hemos dicho, en el papel de la ley como fuente heterónoma del sistema negociador.

En el capítulo siguiente estudiaremos el caso español. Posteriormente el francés, para luego reflexionar acerca del rol del legislador en el procedimiento de negociación colectiva y las virtudes y defectos de ambos sistemas. Finalmente, realizaremos algunas conclusiones de síntesis.

\section{EL CASO ESPAÑOL}

En España la tasa de cobertura de la negociación colectiva superaba el $70 \%$ en el 2013, según estadísticas oficiales ${ }^{21}$.

Encontramos una regulación bastante detallada de la negociación colectiva en el Estatuto de Trabajadores, sin perjuicio de que está también contemplada como un derecho en la Constitución española de $1978^{22}$.

${ }^{18}$ Ermida Uriarte, Óscar, Las Relaciones del Trabajo en América Latina (Lima, Crítica \& Comunicación, Oficina Regional de la OIT para América Latina y el Caribe, 1991), p. 6.

${ }^{19}$ Ermida Uriarte, Óscar, Introducción, en Cuarenta Estudios sobre la Nueva Legislación Laboral Uruguaya, XXXV aniversario del Grupo de los Miércoles (Montevideo, Fundación de Cultura Universitaria, 2010), pp. 5-12. El autor concluye que el modelo uruguayo es de intervencionismo moderado luego de la ley $\mathrm{N}^{\circ} 18.566$ de 2009 (p. 12).

${ }^{20}$ Giugni, Gino, Diritto Sindacale (actualizado por Lauralba Bellardi, Pietro Curzio y Vito Leccese, Bari, Cacucci, 2015).

${ }^{21}$ Martínez-Matute, Marta, La Cobertura de la Negociación Colectiva en España: Una nueva propuesta de medición, en Revista de Economía Laboral 13 (2016), 2, p. 39.

${ }^{22}$ Art. 37.1 de la Constitución española el cual estatuye: "La ley garantizará el 
Dentro de esta normativa es posible pactar convenios colectivos de rama con eficacia erga omnes. Es decir, la ley atribuye eficacia general a los convenios colectivos estatutarios (regulados por dicho estatuto) que someten a las exigencias legales ${ }^{23}$.

También están los convenios extraestatutarios, cuya eficacia personal es limitada y que no serán objeto de nuestro estudio ${ }^{24}$.

La tipicidad de convenios colectivos estatutarios, en el derecho español, es bastante diversa. Los convenios colectivos estatutarios pueden ser acuerdos interprofesionales sobre materias concretas, los convenios marco y los convenios colectivos ordinarios ${ }^{25}$. En este trabajo nos centraremos en estos últimos a nivel supraempresarial o de sector.

El convenio colectivo estatutario (ordinario) dispone de eficacia personal general o erga omnes, es decir obliga a todos los empresarios y trabajadores incluidos dentro de su ámbito de aplicación y durante todo el tiempo de su vigencia (artículo 82.3 del Estatuto de Trabajadores, en adelante LET), regulando las condiciones de trabajo y de productividad (artículo 82.2 LET) y, en general, todas las demás materias que afecten al ámbito de las relaciones de los trabajadores y sus organizaciones representativas con el empresarios y asociaciones empresariales ${ }^{26}$.

En cuanto a las unidades de negociación, rige el principio de libre elección para las partes del convenio. De esta forma, ellas determinan el ámbito de aplicación del convenio, en lo personal, funcional y territorial, los que conjuntamente delimitan la unidad de negociación ${ }^{27}$. El ámbito funcional identifica la rama, el sector o subsector de la actividad económica, la empresa o centro de trabajo e, incluso, el ámbito interprofesional ${ }^{28}$. El ámbito territorial determina el espacio geográfico (estatal, de Comunidad Autónoma, interprovincial, provincial, comarcal o local) en el que se aplica el convenio ${ }^{29}$. El ámbito personal se refiere a la posibilidad de que el convenio comprenda a determinados grupos o categorías de

derecho a la negociación colectiva laboral entre los representantes de los trabajadores y empresarios, asi como la fuerza vinculante de los convenios". Véase PALOMEQUE LóPEZ, Manoel-Carlos, Derecho Sindical ( $3^{a}$ edición, revisada por Djamil Tony Kahale Carrillo, Madrid, Centro de Estudios Financieros, 2016), pp. 172-173.

${ }^{23}$ PalOMeQue, cit. (n. 22), p. 172.

${ }^{24}$ Vicente Palacio, Arántzazu, Manual de Derecho Sindical (4a edición, Barcelona, Atelier, 2017), p. 238.

${ }^{25}$ Sala Franco, Tomás, Derecho Sindical (2a edición, Valencia, Tirant lo Blanch, 2017), pp. 198 ss.

${ }^{26}$ Palomeque, cit. (n. 22), p. 196.

${ }^{27}$ SALA, cit. (n. 25), p. 209.

${ }^{28}$ SALA, cit. (n. 25), p. 209.

${ }^{29}$ SALA, cit. (n. 25), p. 210. 
profesionales existentes en la empresa. Por ejemplo, se admite la exclusión de los altos cargos, del personal directivo y de determinadas categorías de profesionales, siempre y cuando dichos trabajadores gocen por separado de la suficiente capacidad para negociar colectivamente por separado sus propias condiciones de trabajo ${ }^{30}$.

El contenido de los convenios adopta la clásica distinción entre contenido normativo y obligacional, sin perjuicio de cierto contenido mínimo determinado por ley, que la doctrina denomina cláusulas delimitadoras, normas de configuración o contenido formal del mismo ${ }^{31}$.

En cuanto a las partes de los convenios estatutarios, el estatuto de trabajadores exige una representatividad especial teniendo en cuenta el efecto erga omnes de los mismos. En efecto, se requiere de una triple legitimación, a saber, la que habilita para negociar (art. 87 LET), la que capacita para constituir la comisión negociadora (art. 88 LET) y la que se exige para dar validez a los acuerdos adoptados (art. 89.3 LET) ${ }^{32}$.

Para negociar convenios colectivos supraempresariales por el lado trabajador, están legitimados los sindicatos más representativos a nivel estatal y los sindicatos afiliados, federados o confederados a los mismos, en sus respectivos ámbitos. Respecto de los convenios que no exceden de la Comunidad Autónoma están legitimados los sindicatos más representativos a dicho nivel y los sindicatos afiliados, federados o confederados a los mismos, en sus respectivos ámbitos. Por último, también están legitimados los sindicatos que, sin ser los más representativos ni estar afiliados, cuenten con un mínimo del $10 \%$ de los miembros de los Comités de Empresa o Delegados de Personal en el ámbito geográfico y funcional a que se refiere en convenio ${ }^{33}$.

Por la parte empresarial, están legitimadas para negociar las asociaciones empresariales que en el ámbito geográfico y funcional del convenio cuenten con un $10 \%$ de los empresarios que tengan trabajadores subordinados a su cargo, siempre que den ocupación a igual porcentaje de los trabajadores afectados, así como aquellas agrupaciones empresariales que en dicho ámbito den ocupación al 15\% de los trabajadores afectados. Si no hubiere agrupaciones empresariales legitimadas, lo serán las aquellas de ámbito estatal que cuenten con el $10 \%$ o más de las empresas o trabajadores en el ámbito estatal, así como las de Comunidad Autónoma que cuenten un mínimo del 15\% de las empresas o trabajadores. También se encuentran legitimadas para negociar convenios de ámbito estatal, los

\footnotetext{
${ }^{30}$ SALA, cit. (n. 25), p. 210.

${ }^{31}$ SAlA, cit. (n. 25), pp. 272-281.

${ }^{32}$ ViCENTE, cit. (n. 24), p. 255.

${ }^{33}$ VICENTE, cit. (n. 24), pp. 255-256.
} 
sindicatos más representativos a nivel de Comunidad Autónoma y las asociaciones profesionales que cuenten con un mínimo del 15\% de los empresarios y de los trabajadores de la respectiva Comunidad ${ }^{34}$.

Las organizaciones que no alcancen estos niveles de legitimidad siempre pueden negociar por vía del convenio extraestatutario, además de poder adherirse a un convenio ya celebrado ${ }^{35}$.

El Estatuto de Trabajadores exige, además, una legitimación especial para constituir la comisión negociadora a los sindicatos y asociaciones empresariales con la legitimidad ya explicada. Esta legitimación especial consiste en que representen por sí mismos o coaligados, como mínimo, a la mayoría absoluta de los miembros de los Comités de Empresa y delegados de personal, en su caso, y a empresarios que ocupen a la mayoría de los trabajadores afectados por el convenio. En el caso de los sectores en que no haya órganos de representación de los trabajadores, se tendrá por válidamente constituida la comisión negociadora cuando esté integrada por los sindicatos que ostenten la condición de más representativos en el ámbito estatal o de Comunidad Autónoma ${ }^{36}$.

Por último y como ya mencionamos, se exige para dar validez a los acuerdos adoptados el voto favorable, dentro de la comisión negociadora, de la mayoría de cada una de las dos representaciones de trabajadores y empleadores (artículo 89.3 LET) ${ }^{37}$.

El Estatuto de Trabajadores regula con cierto detalle el procedimiento negociador (artículos 89 y 90), por medio de trámites estrictos y formalizados, articulándose a través de diferentes etapas ${ }^{38}$.

El inicio de las negociaciones se produce con una comunicación a la contraparte, por escrito, por parte de alguno de los sujetos legitimados para negociar. Esta comunicación deberá contener la legitimación que se ostenta, los ámbitos del convenio y las materias a tratar (tabla o plataforma reivindicativa) ${ }^{39}$. Si la propuesta de negociación es el resultado de la denuncia de un convenio vigente esta comunicación deberá ser simultánea al acto de denuncia. Copia de la comunicación deberá enviarse a la autoridad laboral para su registro ${ }^{40}$.

La parte receptora de la comunicación deberá contestar por escrito

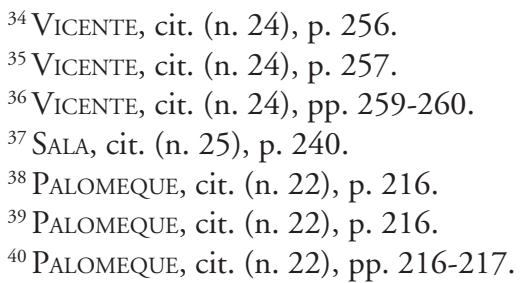


y motivadamente ${ }^{41}$ y tiene la obligación de negociar de buena fe. Esto no implica que deba contratar, pero sí que se realiza un intercambio de ofertas y contraofertas, poniendo a disposición toda la información necesaria y facilitando explicaciones sobre las propuestas presentadas, es decir, la obligación de negociar no es un simple "acto trámite" sino que conlleva un mínimo de coherencia de posiciones ${ }^{42}$.

La negociación es configurada legalmente como un mecanismo de regulación y solución pacífica de conflictos laborales, quedando por ello radicalmente prohibida la violencia sobre las personas y las cosas durante las deliberaciones, pudiendo suspenderse la negociación en curso hasta su desaparición (artículo 89.1 LET) ${ }^{43}$.

En el plazo máximo de un mes, desde la recepción de la comunicación, se procederá a la constitución de la comisión negociadora del convenio. Ambas partes deberán establecer un calendario o plan de negociación y cada parte designará a los miembros de la comisión sin que se pueda exceder de 15 personas por cada parte en los convenios sectoriales. Además, las partes podrán designar libremente y de común acuerdo un presidente de la comisión que tendrá derecho a voz pero no a voto. En caso contrario, es decir si se decidiera no contar con un presidente, la comisión deberá consignar en el acta de la sesión constitutiva los procedimientos a emplear para moderar las sesiones y un representante de la comisión deberá firmar las actas de las sesiones junto al secretario, si lo hubiere ${ }^{44}$.

Cada parte podrá tener asesores con derecho a voz pero sin voto. Además, en cualquier momento de la negociación las partes, de común acuerdo, pueden designar a un mediador para que intervenga $a^{45}$. El contenido de las actas no posee un carácter vinculante para las partes, a diferencia del acuerdo final. En otras palabras, los preacuerdos no son obligatorios o definitivos ${ }^{46}$.

Los debates y el proceso negociador se desarrollarán sin sujeción a trámites y formalidades, salvo el principio de buena fe ya comentado anteriormente, y la exigencia, también ya mencionada, de que los

${ }^{41}$ Palomeque, cit. (n. 22), p. 217.

${ }^{42}$ Monereo Pérez, José Luis - Molina Navarrete, Cristóbal - Moreno Vida, María Nieves, Manual de Derecho Sindical (12 a edición, Granada, Comares, 2017), p. 230.

${ }^{43}$ Monereo - Molina - Moreno, cit. (n. 42), p. 231.

${ }^{44}$ Palomeque, cit. (n. 22), pp. 217-218.

${ }^{45}$ Palomeque, cit. (n. 22), p. 218.

${ }^{46}$ Salido Banús, José Luis, Manual de Derecho Sindical (4a edición, Barcelona, Atelier, 2017), p. 292. 
acuerdos se adopten por el voto favorable de la mayoría de cada una de las representaciones de trabajadores y empleadores ${ }^{47}$.

Como ya hemos expresado no es obligatorio contratar, por tanto, podrían finalizarse las conversaciones sin un acuerdo para convenir, sin que proceda otra actuación. En el caso de que se hubiera denunciado un convenio en vigor, transcurrido un año sin que se haya celebrado otro o dictado un laudo arbitral, perderá el convenio denunciado vigencia salvo pacto en contrario. En estos casos e aplicará, si lo hubiere, el convenio colectivo de ámbito superior ${ }^{48}$ y si no lo hubiere el Tribunal Supremo ha sostenido que las cláusulas del convenio colectivo anterior mantiene vigencia con carácter contractual individual y serán susceptibles de modificaciones sustanciales por parte del empresario ${ }^{49}$.

Obviamente la ruptura de las negociaciones puede implicar que los trabajadores declaren la huelga o planteen un conflicto colectivo de intereses ${ }^{50}$.

Si del proceso negociador resulta, por el contrario, un convenio, este deberá formalizarse por escrito bajo sanción de nulidad. El convenio deberá ser presentado en el plazo de 15 días a partir de la firma ante la autoridad laboral territorialmente competente, para el solo efectos de su registro. Con todo, la autoridad laboral precederá a un examen de legalidad del convenio (adecuación al ordenamiento jurídico) con el fin de disponer su inscripción en el registro correspondiente y su depósito en el órgano público competente ${ }^{51}$. Asimismo, se publicará en el Boletín Oficial correspondiente a su ámbito territorial dentro del plazo de 20 días desde la presentación del convenio ${ }^{52}$.

Por el contrario, si considera que el convenio colectivo conculca la legalidad vigente deberá dirigirse de oficio a la jurisdicción laboral ${ }^{53}$. También existen otras vías de impugnación como el procedimiento de conflicto colectivo (por ilegalidad o lesividad a terceros), impugnación indirecta y recurso de amparo ${ }^{54}$.

La legislación española contempla la posibilidad de adhesión a un

\footnotetext{
${ }^{47}$ Palomeque, cit. (n. 22), p. 218.

${ }^{48}$ Palomeque, cit. (n. 22), p. 219.

${ }^{49}$ SALA, cit. (n. 25), p. 254. El artículo 41 LET regula las modificaciones sustanciales por parte del empresario, una especie de derecho da variación.

${ }^{50}$ Monereo - Molina - Moreno, cit. (n. 42), p. 231. Sobre el conflicto colectivo véase SALA, cit. (n. 25), pp. 393 ss.

${ }^{51}$ Palomeque, cit. (n. 22), p. 219.

${ }^{52}$ Palomeque, cit. (n. 22), p. 220.

${ }^{53}$ Salido, cit. (n. 46), pp. 299-300.

${ }^{54}$ Salido, cit. (n. 46), pp. 300-303.
} 
convenio colectivo ya pactado ${ }^{55}$ y la extensión del convenio por un acto de la administración pública ${ }^{56}$. Como explicamos en la introducción a este artículo, en materia de extensión revisaremos el caso francés, donde encontramos el origen de esta modalidad ${ }^{57}$.

Con las enmiendas del gobierno de Rajoy se han contemplado algunas excepciones a la eficacia personal erga omnes. En efecto, por acuerdo de la empresa y los representantes de los trabajadores legitimados para negociar un convenio colectivo de empresa (artículo 87.1 LET), cuando concurran causas económicas, técnicas, organizativas de producción, se podrá proceder, luego de un período de consultas, a la inaplicación en la empresa o descuelgue de la misma respecto del convenio colectivo sectorial y también de empresa ${ }^{58}$. Este descuelgue puede comprender las siguientes materias (artículo 82.3 LET):

a) Jornada de trabajo.

b) Horario y distribución del tiempo de trabajo.

c) Régimen de trabajo a turnos.

d) Sistema de remuneración y cuantía salarial.

e) Sistema de trabajo y rendimiento.

f) Funciones, cuando excedan de los límites que para la movilidad funcional prevé el artículo 39.

g) Mejoras voluntarias de la acción protectora de la Seguridad Social.

Este acuerdo de inaplicación deberá respecta el principio de igualdad de género y no podrá tener efecto retroactivo ${ }^{59}$.

Antes de la reforma de 2012 ya existían acuerdos de inaplicación o descuelgue del convenio sectorial a nivel de empresa, pero estaban limitados sólo al ámbito, salarial aunque en reformas posteriores se fue ampliando paulatinamente su procedencia. ${ }^{60}$ Sin embargo, con la reforma del 2012, se produce un cambio cualitativo y de envergadura en la medida de que el descuelgue no queda inserto dentro de una lógica de flexibilidad negociada colectivamente a nivel de empresa, ya que con

${ }^{55}$ Monereo - Molina - Moreno, cit. (n. 42), pp. 218-219.

${ }^{56}$ Montoya Melgar, Alfredo, Derecho del Trabajo (38 a edición, Madrid, Tecnos, 2017), pp. 184-185.

${ }^{57}$ Salido, cit. (n. 46), p. 307.

${ }^{58}$ Palomeque, cit. (n. 22), p. 196.

${ }^{59}$ SALA, cit. (n. 25), p. 290.

${ }^{60}$ Cruz Villalón, Jesús, El Descuelgue de Condiciones Pactadas en Convenio Colectivo tras la Reforma de 2012, en Revista de Derecho Social 57 (2012), pp. 231232. 
la reforma se permite la inaplicación incluso cuando no hay acuerdo de los trabajadores. Es decir, ante la falta de acuerdo puede recurrirse a la Comisión Consultiva Nacional de Convenios Colectivos u otro órgano similar en el ámbito de las Comunidades Autónomas, para que se decida el descuelgue ${ }^{61}$ por medio de un arbitraje obligatorio público solicitado por la dirección de la empresa, y resuelto por la Administración Pública previa audiencia de las organizaciones sindicales y empresariales ${ }^{62}$.

Comentando esta reforma Antonio Baylos denuncia que esta normativa insulta la buena fe de los sindicatos, conlleva un deterioro paulatino de la estabilidad normativa y vulnera importantes principios constitucionales $^{63}$. En el mismo sentido Julia López ha enfatizado la ruptura del modelo constitucional y la vulneración de los estándares internacionales con la reforma del $2012^{64}$. Además, se ha denunciado el lastre ideológico neoliberal de la reforma y su ineptitud para crear empleo, falacia que es la principal justificación de esta normativa ${ }^{65}$.

La reforma para algunos es tributaria de un contexto donde la flexibilidad es un dogma indiscutible y el rol de las reformas legales es adaptar el sistema negociador a la difícil coyuntura económica, desregulando y descentralizando la negociación colectiva ${ }^{66}$.

\section{EL CASO FRANCÉS}

El caso francés resulta de particular interés ya que la cobertura de la negociación colectiva es muy alta, más de un $95 \%$ de los trabajadores en el año $2013^{67}$. Lo anterior, debido a que los convenios colectivos son fácilmente extendidos a sectores de actividad en su totalidad. En efecto, el gobierno puede extender convenios colectivos a solicitud de una de las partes que negociaron. Estas extensiones, decididas por la autoridad

\footnotetext{
${ }^{61}$ CruZ, cit. (n. 60), p. 233.

${ }^{62}$ Cruz, cit. (n. 60), p. 242.

${ }^{63}$ Baylos Grau, Antonio, El Sentido General de la Reforma: La Ruptura de los Equilibrios Organizativos y Colectivos y la Exaltación del Poder Privado del Empresario, en Revista de Derecho Social 57 (2012), pp. 10-11.

${ }^{64}$ López, Julia, Elementos de Definición del Modelo de Relaciones Laborales por las Normas de la OIT y Comunitarias: la Desestabilización por la Reforma Laboral (2012), en Revista de Derecho Social 57 (2012), pp. 38 ss.

${ }^{65}$ Urrutikoetxea Barrutia, Mikel, El Preámbulo del RD Ley 3/2012, o las Retóricas de la Manipulación, en Revista de Derecho Social 57 (2012), p. 20.

${ }^{66}$ Correa Carrasco, Manuel, La Ordenación de la Estructura de la Negociación Colectiva tras las Recientes Reformas Laborales, en Revista de Derecho Social 59 (2012),
} p. 42.

${ }^{67}$ Martínez-Matute, cit. (n. 21), p. 39. 
pública, han sido usadas en diferentes ramas para subir el nivel de los beneficios entregados a trabajadores y para evitar la competencia basada en bajo precio de la mano de obra ${ }^{68}$.

Otro mecanismo parecido que también estudiaremos son las ampliaciones (élargissement) del convenio ramal, por parte de la autoridad, a diferentes regiones o a otros sectores económicos.

En consecuencia, incluso las compañías que no son miembros en una organización de empleadores son cubiertas por un acuerdo sectorial una vez que ha sido extendido o ampliado por el gobierno ${ }^{69}$.

Con las "Ordenanzas Macron" de 201770, se introduce un cambio en la lógica de cómo entender la articulación entre las normas que emanan de la negociación colectiva, entre otras materias. En este apartado, como ya hemos explicado anteriormente, nos referiremos a la extensión de beneficios y a la ampliación dentro del modelo francés, como un buen ejemplo del segundo tipo de mecanismo descrito en la taxonomía de Giugni, a diferencia del caso español, que hemos estudiado como ejemplo del primer tipo, es decir, de reconocimiento a los actores sociales del poder de dictar normas vinculantes para todos los sujetos incluidos en el ámbito del contrato o convenio. Para cumplir este cometido, revisaremos algunas nociones básicas del sistema francés, para luego referirnos al sistema de extensión de beneficios y de ampliación de los mismos, finalizando con algunas referencias a la reforma Macron y sus efectos.

Lo primero que debemos establecer es la concepción francesa sobre convenio colectivo. Auzero, Baugard y Dockès definen al convenio colectivo como "un acuerdo celebrado entre un empleador o un grupo de empleadores y una o más organizaciones sindicales representativas de trabajadores, con el objetivo de establecer conjuntamente las condiciones

${ }^{68}$ Auzero, Gilles - BAugard, Dirk - Dockès, Emmanuel, Droit du travail (Paris, Dalloz, 2018),

${ }^{69}$ KerCKHOFs, Peter, Extension of collective agreements in the EU (Eurofound, 2011), p. 6. Disponible [en línea]: https://www.eurofound.europa.eu/publications/ customised-report/2011/industrial-relations/extension-of-collective-bargainingagreements-in-the-eu-background-paper (visitada el 24 de julio de 2018).

${ }^{70}$ Véase: Lyon-CaEn, Antoine, Ordonnances Macron, Commentaires pratiques et nouvelles dispositions du code du travail (Dalloz, Paris, 2018); Jeammaud, Antoine, La "Reforma Macron» del Código del Trabajo francés, en Revista Derecho del Trabajo 6 (2018), 18, pp. 7-37.

${ }^{\mathrm{El}}$ artículo 38 de la Constitución francesa permite que el gobierno solicite una autorización al Parlamento para dictar ordenanzas sobre materias propias de ley por un plazo limitado. Para estos efectos el Parlamento dicta una ley de habilitación y sólo tienen valor reglamentario hasta que son aprobadas posteriormente por una ley. 
de empleo y de trabajo, así como las garantías sociales" ${ }^{71}$. Verdier, Coeuret y Souriac, por su parte, lo definen como "un acuerdo mediante el cual uno o más sindicatos representativos de trabajadores y uno o más grupos de empleadores o empleadores individuales establecen las condiciones de empleo, formación profesional y de trabajo, garantías sociales y obligaciones de los firmantes del acuerdo"72.

El convenio colectivo ha sido entendido por la doctrina como un acuerdo creador de normas, de reglas, una fuente de reglas ${ }^{73}$. Es considerado como contrato desde su conclusión. Tiene fuerza obligatoria para sus co-firmantes ${ }^{74}$. Sin embargo, en cuanto a su aplicación, el convenio es tratado como un reglamento. En palabras de Couturier se trata de su "dimensión reglamentaria"75.

Por otro lado, el juez debe aplicar esta regla de derecho de la misma manera que la ley. Para el caso que un trabajador no fundamente su demanda en un convenio determinado, el juez debe buscar si hay un convenio colectivo aplicable $y$, eventualmente, determinar su contenido ${ }^{76}$. A este efecto normativo se deben agregar los efectos inmediato, imperativo y automático de los convenios colectivos ${ }^{77}$.

Originado en la práctica social y comúnmente destinado a ponerle término a un conflicto colectivo, los primeros acuerdos colectivos no presentaban una forma jurídica precisa y los esfuerzos doctrinarios para encasillarlos en categorías o en mecanismos tradicionales no eran del todo convincentes $^{78}$. Es aquí donde aparece la naturaleza híbrida del convenio colectivo que es contrato y a la vez acto reglamentario ${ }^{79}$.

Este poder creador de normas jurídicas emana de un derecho constitucional establecido en el preámbulo de la Constitución de 1946. Se trata

${ }^{71}$ AuZERO - BAUgard - Dockès, cit. (n. 68), p. 1532.

${ }^{72}$ Verdier, Jean-Maurice - Coeuret, Alain - Souriac, Marie-Armelle, Droit $d u$ Travail (París, Dalloz, 2005), I, p. 185.

${ }^{73}$ Couturier, Gérard, Traité de droit du travail, 2/ Les relations collectives du travail (París, Presses Universitaires de Paris, 2001), p. 488.

${ }^{74}$ Auzero - Baugard - Dockès, cit. (n. 68), p. 1532, y Couturier, cit. (n. 73), pp. 487-488.

${ }^{75}$ Couturier, cit. (n. 73), p. 490.

${ }^{76}$ Auzero - Baugard - Dockès, cit. (n. 68), p. 1533.

${ }_{77}$ Para profundizar sobre estos efectos véase: Auzero - BAUgard - DockÈs, cit. (n. 68), pp. 1577 ss.; y COUTURIER, cit. (n. 73), pp. 499-500.

${ }^{78}$ CanUt, Florence - Verkindt, Pierre-Yves, Négocier sous contrainte. Un nouveau visage de la négociation collective en France?, en Mélanges en l'honneur du Professeur François Gaudu, Droit du travail, Emploi, Entreprise (Collection Bibliothèque de l'IRJS - André Tunc, Paris, IRJS Editions, 2014), p. 243.

${ }^{79}$ CANUt - Verkindt, cit. (n. 78), p. 244. 
del derecho a la negociación colectiva ${ }^{80}$. La evolución legal del modelo francés ha pasado por diversas etapas ${ }^{81}$.

La especificidad del convenio colectivo francés fue estatuida por el legislador en la ley del 24 de junio de 1936, lo cual provocó un aumento sin precedentes de esta técnica en Francia. El contenido del convenio, aunque libremente decidido por las partes contratantes, debía comprender varias cláusulas esenciales relativas a la relación de trabajo y la innovación más atrevida del legislador de 1936 fue haber permitido a la autoridad pública proceder por decreto ministerial a la extensión del convenio colectivo, desde el momento en que era firmado por los sindicatos y grupos de empleadores representativos, considerados como portavoces de la profesión ${ }^{82}$.

Luego se adoptaron importantes leyes que han modificado la regulación de los convenios colectivos, manteniendo y profundizando el modelo de extensión. Podemos mencionar la ley de 13 de julio de 1971, o la ley Fillon de 4 de mayo de 2004. Asimismo, es de interés la ley de 5 de marzo de 2014, relativa a la formación profesional, el empleo y la democracia social, en la cual se estableció que las organizaciones profesionales de empleadores mayoritarias no podían rechazar u oponerse a lo regulado por el convenio en estas materias.

En cuanto al tema que estamos estudiando, es decir la extensión y el rol de la ley (más adelante veremos en qué consiste la ampliación), debemos decir que se concreta en la posibilidad que tienen los actores sociales que han pactado un convenio colectivo de rama o un acuerdo profesional o interprofesional o el Estado, a través del Ministerio del Trabajo, de ampliar el campo de aplicación de lo acordado mediante un procedimiento administrativo en el Ministerio del Trabajo y siempre que se cuente con un informe favorable de la Comisión Nacional de Negociación Colectiva ${ }^{83}$.

Para que un convenio colectivo sea susceptible de extensión debe haberse acordado con ciertos requisitos. Debe haber sido negociado en el seno de una comisión paritaria o mixta, compuesta obligatoriamente por representantes de los empleadores y trabajadores que sean representativos ${ }^{84}$

${ }^{80}$ Couturier, cit. (n. 73), p. 489.

${ }^{81}$ Para profundizar sobre la evolución véase AUZERO - BAUGARD - Dockès, cit. (n. 68), pp. 1533-1541.

${ }^{82}$ AuZero - Baugard - Dockès, cit. (n. 68), p. 1651.

${ }^{83}$ Artículo L2261-24 del Código del Trabajo francés.

${ }^{84}$ Las organizaciones representativas son determinada mediante un acto administrativo. Así las actuales organizaciones de trabajadores representativas fueron fijadas mediante una decisión administrativa el 22 de junio de 2017, publicada en el Diario oficial el 30 de junio de 2017. Las organizaciones que se incluyen son: la Confédération française démocratique du travail (CFDT) ; la Confédération générale du travail (CGT) ; la Confédération générale du travail-Force ouvrière (CGT-FO) 
del campo de aplicación respectivo ${ }^{85}$. La comisión es paritaria si está conformada sólo por representantes de las partes. La comisión también puede ser tripartita, en cuyo caso comprende un representante de la Administración que la Preside ${ }^{86}$. La convocatoria a esta comisión puede ser realizada de oficio por el Ministerio del Trabajo o a petición de una organización de empleadores o de trabajadores que sea representativa. El Ministerio está obligado a convocarla si la solicitud es efectuada por dos organizaciones de empleadores o de trabajadores que sean representativas ${ }^{87}$.

Aunque la autoridad administrativa puede enfocar sus esfuerzos en llegar a un acuerdo, son las partes las que, en base a su libertad contractual, deciden finalmente suscribir o no un convenio que luego podrá ser extendido por el Ministerio del Trabajo ${ }^{88}$. Si la convención no es suscrita por todas las organizaciones representativas, para que proceda la extensión los no signatarios deben haber sido convocados y estado presente en la comisión mixta aunque no hayan firmado el texto finalmente acordado ${ }^{89}$. Con todo, no puede ser extendido un convenio de rama o acuerdo si existe una oposición formal y fundada de una o más organizaciones profesionales de empleadores representativos que empleen a más del $50 \%$ de todos los trabajadores del nivel respectivo. Esta oposición debe plantearse dentro del plazo de un mes a partir de la publicación por la autoridad administrativa de la extensión en el Diario Oficial arts. L. 2231-5 y L. 2231-69 ${ }^{90}$. Esta oposición es una de las enmiendas de las Ordenanzas Macron, a favor de los empleadores ${ }^{91}$.

; la Confédération française de l'encadrement-Confédération générale des cadres (CFE-CGC) ; y la Confédération française des travailleurs chrétiens (CFTC).

Los criterios para establecer la representatividad se encuentran en los artículos L2121-1 aL2122-13 del Código del Trabajo. Los criterios generales de representatividad están en el artículo L2121-1 según el cual la representatividad de las organizaciones sindicales se determina según los siguientes criterios acumulativos: (1) el respeto por los valores republicanos; (2) la independencia; (3) la transparencia financiera; (4) una antigüedad mínima de dos años en el campo profesional y geográfico que cubre el nivel de negociación. Esta antigüedad se evalúa a partir de la fecha de depósito legal de los estatutos; (5) la audiencia establecida de acuerdo con los niveles de negociación de conformidad con los artículos L. 2122-1, L. 2122-5, L. 2122-6 y L. 2122-9; (6) la influencia, caracterizada principalmente por la actividad y la experiencia, $\mathrm{y} 7^{\circ} \mathrm{La}$ cantidad de miembros y las cotizaciones sindicales.

${ }^{85}$ AuZero - Baugard - Dockès, cit. (n. 68), p. 1652.

${ }^{86}$ Auzero - Baugard - Dockès, cit. (n. 68), p. 1652.

${ }^{87}$ Auzero - Baugard - Dockès, cit. (n. 68), p. 1652.

${ }^{88}$ Auzero, Gilles et al., Droit du travail, cit. (68), p. 1652.

${ }^{89}$ Auzero - Baugard - Dockès, cit. (n. 68), p. 1653.

${ }^{90}$ Auzero - Baugard - Dockès, cit. (n. 68), p. 1654.

${ }^{91}$ Lyon-Caen, cit. (n. 70), p. 61. 
Para que opere la extensión el convenio de rama o el acuerdo (profesional o interprofesional) no debe necesariamente ser de carácter nacional. Puede ser de nivel, regional, departamental o local ${ }^{92}$.

Para que un convenio de rama pueda ser extendido, debe contener ciertas cláusulas obligatorias ${ }^{33}$. En el ámbito colectivo, deben comprenderse, por ejemplo, materias relativas al ejercicio de los derechos sindicales, las representación electiva del personal a nivel de empresa, los mandatos de representación y negociación de la rama, y los procedimientos convencionales de conciliación en materia de conflictos colectivos del trabajo. En el ámbito del derecho individual, debe considerar, por ejemplo, las clasificaciones profesionales, las vacaciones, la ruptura del contrato de trabajo, la formación profesional, la igualdad de trato, las condiciones especiales para trabajadores a tiempo parcial, a domicilio, discapacitados, etc. El contenido en sí de estas cláusulas es libremente determinado por las partes. Asimismo, los acuerdos profesionales e interprofesionales pueden ser extendidos aunque versen sólo sobre una materia específica ${ }^{94}$.

Las Ordenanzas Macron han establecido un requisito extra para que el convenio de rama sea extendible a empresas con menos de 50 trabajadores (art. L. 2232-10-1 del Código del Trabajo francés), consistente en contemplar disposiciones específicas para estas empresas más pequeñas. Si no se contemplan o no se precisan los motivos de por qué no fueron adoptadas estas disposiciones específicas, el convenio de rama no puede ser objeto de extensión por parte de la autoridad ${ }^{95}$. Es justamente esta norma la que constituye para muchos un cambio de paradigma, al permitir que un acuerdo de rama pueda incluir estipulaciones específicas y menos protectoras para las empresas con menos de cincuenta empleados ${ }^{96}$. El empleador puede aplicar este acuerdo en forma unilateral después de

${ }^{92}$ Auzero - Baugard - Dockès, cit. (n. 68), p. 1653.

${ }^{93}$ AuZERO - BAugard - Dockès, cit. (n. 68), p. 1654-1655.

${ }^{94}$ AuZero - Baugard - Dockès, cit. (n. 68), p. 1655.

${ }^{95}$ LyOn-CAEn, cit. (n. 70), p. 60.

${ }^{96}$ En la discusión de la ley de habilitación para dictar las Ordenanzas los representantes del gobierno manifestaron que el Código del Trabajo francés había devenido en un texto "inadaptado" (desenfocado) a la economía de los tiempos actuales e "inadaptado" a las necesidades de las empresas y de los trabajadores. Lo anterior, dado que históricamente fue construido en base a la gran empresa y al empleo de por vida, ignorando por tanto a las pequeña empresa, y porque fue concebido sin reconocer que el empleador y sus trabajadores pueden llegar a acuerdos mejores en su respectivo nivel (de empresa o lugar de trabajo). Según el gobierno de Macron, estas reformas constituyen una renovación y no una ruptura del derecho laboral tradicional, ya que la "inadaptación" no afecta a los principios del Código, pero sí a sus normas de detalle. Véase LYON-CAEN, cit. (n. 70), pp. 2-3. 
haber informado al Comité Económico y Social (si lo hubiera dentro de la empresa ${ }^{97}$, así como también a los trabajadores.

La extensión de un convenio ramal se inicia con una solicitud de las organizaciones interesadas, aunque el Ministerio del Trabajo no está obligado a decretarl ${ }^{98}$. Con todo, la decisión de la administración no es discrecional, ya que puede ser revisada por el juez de lo contencioso administrativo. El rechazo de la extensión puede basarse en motivos de interés general, económicos o sociales, en la protección de terceros y en la intención de reformular una rama de actividad ${ }^{99}$. Las Ordenanzas Macron agregaron la posibilidad de que el Ministerio del trabajo rechace la extensión por razones de interés general, especialmente por afectar en forma excesiva de la libre competencia ${ }^{100}$.

En definitiva, el campo de aplicación de la extensión será el que se indique en el acuerdo o convenio a extender, o como lo determine el Ministerio del Trabajo. Así como también los efectos y las sanciones que se extenderá serán las que fijen las partes o la administración ${ }^{101}$. Por tanto es posible que la extensión se refiera a tan solo algunas partes de un convenio colectivo ramal o de un acuerdo. Incluso puede darse el caso de que el Ministerio extienda, luego de haber escuchado a la Comisión Nacional de Negociación Colectiva, un convenio que no fue firmado por la totalidad de las organizaciones representativa o que no contenga todas las cláusulas obligatorias o que no cubre al conjunto de las categorías profesionales de la rama ${ }^{102}$.

Para efectuar la extensión debe consultarse en forma previa a la Comisión Nacional de Negociación Colectiva ${ }^{103}$, la cual deberá dar una opinión motivada al Ministerio del Trabajo acerca de su conveniencia. También deberá consultarse a esta Comisión cuando se pretenda derogar un decreto de extensión. Si la Comisión da su opinión favorable y no se presentan dos

${ }^{97}$ Las Ordenanzas Macron han unificado tres organismos como representantes del personal en uno solo dentro de la empresa. Es decir delegado de personal, el comité de empresa y el comité de grupo ahora conformarán el Comité Económico y Social. Véase Lyon-CaEn, Antoine, Ordonnances, cit. (70), pp. 107 y ss., y Jeammaud, cit. (n. 70), pp. 23 ss.

${ }^{98}$ AuZERO - BAUGARD - Dockès, cit. (n. 68), p. 1655.

${ }^{99}$ Auzero - Baugard - Dockès, cit. (n. 68), p. 1656.

${ }^{100}$ JeAmmaud, cit. (n. 70), nota 24 en p. 17, y Lyon-CAEN, cit. (n. 70), pp. 61-62.

${ }^{101}$ Artículo L2261-15 del Código del Trabajo francés.

${ }^{102}$ Auzero - Baugard - Dockès, cit. (n. 68), p. 1657.

${ }^{103}$ Integrada por el ministro del trabajo o su representante, quien la preside, y los ministros de agricultura y de economía o sus representantes, el presidente de la sección social del Consejo de Estado, y en número similar los representantes de las organizaciones de trabajadores y empleadores más representativos a nivel nacional. 
organizaciones de empleadores o trabajadores que formalicen su oposición a la extensión, el Ministerio podrá proceder a la misma si se cumplen todos los demás requisitos ${ }^{104}$. Por el contrario, si se presentan dos organizaciones de empleadores o trabajadores manifestando su oposición a la extensión, el Ministerio puede solicitar por segunda vez la opinión del Consejo y con este parecer puede proceder a la extensión incluso en contra de la oposición manifestada por dichas organizaciones ${ }^{105}$.

Una vez recibida la opinión de la Comisión, el Ministerio del Trabajo debe publicar en el Diario oficial un aviso acerca de la extensión que se pretende realizar, invitando las personas $\mathrm{u}$ organizaciones interesadas a hacer observaciones dentro del plazo de 15 días $^{106}$. Con todo, como ya adelantamos, no puede ser extendido un convenio de rama o acuerdo si existe una oposición formal y fundada de una o más organizaciones profesionales de empleadores representativos que empleen a más del 50\% de todos los trabajadores del nivel respectivo. Esta oposición debe plantearse dentro del plazo de un mes a partir de la publicación por la autoridad administrativa de la extensión en el Diario Oficial ${ }^{107}$.

Luego de estos trámites la extensión será realizada pode decreto ministerial el cual será publicado en el Diario oficial junto con la convención o acuerdo extendido. Se trata de un acto administrativo que podrá ser anulado si no se han seguido los procedimientos o si ha habido abuso de $\operatorname{poder}^{108}$.

Los efectos de la extensión son bastante claros: todos los empleadores que ejerzan una actividad dentro del campo de aplicación profesional o geográfico de la extensión deben aplicar y respetar los contenidos del convenio ramal o del acuerdo, sean o no miembros de las organizaciones signatarias de los mismos ${ }^{109}$.

La naturaleza jurídica de la convención o acuerdo extendidos se mantiene a pesar del decreto de extensión ${ }^{110}$.

Como ya precisamos en su oportunidad, una figura bastante similar pero diferente es la ampliación (élargissement) del convenio ramal. Se trata de una técnica jurídica que permite al Ministerio del Trabajo extender el ámbito de aplicación de una convención o acuerdo colectivo ${ }^{111}$ a una

\footnotetext{
${ }^{104}$ Auzero - Baugard - Dockès, cit. (n. 68), p. 1657.

${ }^{105}$ Auzero - Baugard - Dockès, cit. (n. 68), p. 1658.

${ }^{106}$ Auzero - Baugard - Dockès, cit. (n. 68), p. 1658.

${ }^{107}$ Lyon-Caen, cit. (n. 70), p. 61.

${ }^{108}$ AuZERO - BAUgARD - Dockès, cit. (n. 68), p. 1658.

${ }^{109}$ AUZERO - BAUGARD - DockĖs, cit. (n. 68), p. 1658.

${ }^{110}$ AuZERo - BAUgard - Dockès, cit. (n. 68), p. 1659.

${ }^{111}$ Auzero - BAUgard - Dockès, cit. (n. 68), p. 1660.
} 
región o sector distinto ${ }^{112}$. En otras palabras, el decreto de extensión está delimitado a una región o sector en donde ya existe un convenio ramal o acuerdo que será extendido dentro de la misma región o sector al resto de los sujetos. Por el contrario, la función del decreto de ampliación es tomar un convenio ramal o acuerdo de una región o sector $\mathrm{X}$ y aplicarlo a una región o sector $Y$, distinto de X. Por ejemplo, un decreto de extensión dentro del sector eléctrico, significaría aplicar un convenio ramal de dicho sector a otros trabajadores de empresas eléctricas dentro del mismo. Por el contrario, un decreto de ampliación aplicaría el convenio del sector eléctrico a trabajadores de otro sector distinto, por ejemplo, de energía nuclear.

El decreto de ampliación (élargissement) se aplica a un ámbito profesional o geográfico con una imposibilidad persistente para llegar a un convenio colectivo ramal. Y por lo mismo, a diferencia del decreto de extensión, la función de la ampliación es promocional, en el sentido de dar una señal y una suerte de amenaza a los actores sociales de que se les aplicará una convención ramal de otra región o sector si no llegan a un acuerdo. Esta técnica es un instrumento complementario a la extensión ${ }^{113}$.

El requisito del decreto de ampliación es la carencia permanente y prolongada de organizaciones de trabajadores y empleadores en un ámbito determinado (región o sector) lo que conlleva la imposibilidad persistente de llegar a celebrar un convenio colectivo ramal. Para que proceda la ampliación, debe haber condiciones económicas análogas entre los sectores o regiones respectivos ${ }^{114}$. Esto último constituye una de las reformas de las Ordenanzas Macron. En efecto, antes bastaba con "condiciones análogas", pero ahora es más exigente el requisito para la ampliación, de “condiciones económicas análogas"115.

Los decretos de ampliación al igual que los de extensión también deben ser consultados a la Comisión Nacional de Negociación Colectiva, con una publicación previa en el Diario oficial y una nueva publicación definitiva una vez adoptado el decreto ${ }^{116}$. La iniciativa es del Ministerio del trabajo y la ampliación, a diferencia de la extensión, puede ser aprobada incluso en contra de la opinión de la Comisión Nacional de Negociación Colectiva (sin una segunda consulta como en las extensiones $)^{117}$.

La otra enmienda de las Ordenanzas Macron en este tema fue la consagración de la posibilidad de que el Ministerio del trabajo extienda sólo

\footnotetext{
${ }^{112}$ Auzero - Baugard - Dockès, cit. (n. 68), p. 1660.

${ }^{113}$ Auzero - Baugard - Dockès, cit. (n. 68), p. 1651.

${ }^{114}$ AuZERO - BAUgard - Dockès, cit. (n. 68), p. 1660.

${ }^{115}$ Lyon-CAen, cit. (n. 70), p. 63.

${ }^{116}$ Auzero - Baugard - Dockès, cit. (n. 68), p. 1661.

${ }^{117}$ Auzero - Baugard - Dockès, cit. (n. 68), p. 1661.
} 
parcialmente la convención ramal o el acuerdo respectivo, a diferencia de la regulación anterior donde la ampliación comprendía la totalidad de las disposiciones del convenio o acuerdo ampliado ${ }^{118}$.

Los efectos de la ampliación implican la obligatoriedad del convenio ramal ampliado en el nuevo sector y su vigencia se mantendrá hasta que sea derogado por el Ministerio o cuando terminen los efectos del decreto de extensión originario ${ }^{119}$. Por ejemplo, en un sector $\mathrm{X}$ se extiende un convenio ramal y luego este convenio es ampliado al sector $\mathrm{Y}$.

También la ampliación termina cuando los actores sociales, en la región o sector respectivo, firman su propio convenio o acuerdo ${ }^{120}$.

De esta forma, la ampliación constituye una medida de fomento a la negociación $^{121}$.

Ambas modalidades (extensión y ampliación) han sido valoradas positivamente por la doctrina francesa.

Para muchos el mecanismo de extensión ha sido claramente positivo, por ejemplo, Mazeaud señala que "la ventaja de la extensión es respetar las reglas elaboradas por los actores de la vida económica y social, al tiempo que se evita la disparidad de estatus dentro de la misma rama, lo que podría crear dumping social" ${ }^{122}$. Se trata entonces de un efecto corrector de desigualdades elaborado por los mismos actores de la negociación colectiva.

Hasta antes de la reforma Macron, el convenio colectivo de rama tenía prevalencia sobre el de empresa. Es decir, éste sólo podía elevar los beneficios contemplados en el de rama. Este efecto se denominaba principio de favor por la doctrina francesa ${ }^{123}$.

Con la reciente reforma de las Ordenanzas Macron deberá repensarse el modelo francés. En particular en la relación entre los convenios de empresa y de rama. El cambio de paradigma establecido en las Ordenanzas hace pensar en un cambio en la manera cómo se llevará a cabo la extensión de beneficios, gracias al convenio celebrado a nivel de empresa y no en virtud del de rama.

Auzero, criticando las enmiendas de Macron, señala que el predominio de la convención de rama se relativiza. De hecho, el acuerdo de empresa predomina si garantiza a los empleados "al menos garantías equivalentes".

${ }^{118}$ LyOn-CaEn, cit. (n. 70), p. 63.

${ }^{119}$ AuZERo - BAUgard - Dockès, cit. (n. 68), p. 1661.

${ }^{120}$ AuZero - BAUgard - Dockès, cit. (n. 68), pp. 1661-1662.

${ }^{121}$ AuZERo - BAUgard - Dockès, cit. (n. 68), p. 1662.

${ }^{122}$ Mazeaud, Antoine, Droit du Travail (París, Montchrestien, 2004), p. 187.

${ }^{123}$ VACHET, Gérard, Le principe de faveur dans les rapports entre sources de droit, en Teyssié, Bernard (dir.), Les Principes Dans la Jurisprudence de la Chambre Sociale de la Cour de Cassation (París, Dalloz, 2008), pp. 79-93. 
Esta nueva regla de articulación de las normas convencionales en cuestión, que reemplaza el principio de favor, llena de incertidumbre a los actores del sistema en cuanto a su implementación ${ }^{124}$.

La doctrina ha manifestado opiniones diversas frente a las enmiendas de las Ordenanzas Macron.

Antoine Jeammaud señala que la regla de principio permanece sin cambios y contempla que una o varias organizaciones sindicales representativas de trabajadores, a través de los delegados sindicales por ellas designados, negocian, firman y revisan los convenios y acuerdos colectivos de trabajo en las empresas o centros de trabajo. Sin embargo, de forma progresiva, se han introducido diferentes fórmulas para permitir la celebración de acuerdos en empresas -- pequeñas y medianas sobre todo-- sin delegado sindical, sea que su plantilla no alcance el umbral mínimo para proceder a su designación, o sea que ninguna organización haya estimado útil designarlo. En este marco, se abren posibilidades de negociar a través de los representantes elegidos (delegados del personal, miembros del comité de empresa) o de trabajadores "ordinarios" con un mandato a tal efecto por parte de sindicatos representativos ${ }^{125}$.

Según los redactores de la última reforma se ha querido ir más allá y proporcionar soluciones pragmáticas en las muy pequeñas y medianas empresas, como una suerte de derecho a la negociación colectiva de las pequeñas y medianas empresas, garantizado por un acceso directo y simple a la negociación para todas las empresas del país, así como de un derecho universal, es decir, relativo a todos los temas abiertos a la negociación ${ }^{126}$.

Por su parte, Patrice Adam va más lejos en sus críticas indicando que con las reformas reinará la convención de empresa, lo que provocará un efecto centrífugo potente desde el convenio de rama hacia sus márgenes. De esta forma, el papel del convenio de rama ya no será el de ayer, es decir, luego de haber sido un gendarme, es ahora un rey caído que se convirtió en una ayuda de cámara al servicio de las pequeñas y medianas empresas ${ }^{127}$.

Una opinión más matizada es la de Françoise Favennec-Hery quien sostiene que para permitir que las PYME se adapten a la realidad cambiante, las ordenanzas de Macron adoptan una lógica de asimilación: poner la ley al alcance de las pequeñas empresas, favorecer la celebración de convenios

${ }^{124}$ Auzero, Gilles, Conventions d'entreprise et conventions de branche, en Droit social 12 (2017), p. 1018.

${ }^{125}$ JEAMMAUd, cit. (n. 70), p. 18.

${ }^{126}$ JeAMmaUd, cit. (n. 70), p. 18.

${ }^{127}$ AdAM, Patrice, L'accord de branche, en Droit social 12 (2017), p. 1039. 
colectivos y flexibilizar el empleo. De esta forma, finalmente se escucha a las PYME ${ }^{128}$.

Frente a la cuestión de saber si es un paradigma nuevo Frédéric Gea señala que ello dependerá de si existe o no la convicción de que será mejor que el anterior ${ }^{129}$.

En este punto Jeammaud manifiesta que parece absurdo hablar de "destrucción del Derecho del Trabajo" como se ha llegado a afirmar, porque el Derecho del Trabajo francés experimenta desde principios del siglo XXI una evolución globalmente favorable a los empleadores, aunque todas las innovaciones, incluso las más recientes, no vayan en el mismo sentido ${ }^{130}$.

Cabe preguntarse, por otra parte, por el rol de la autoridad pública en materia de extensión, porque se trata de una decisión administrativa que se efectúa a solicitud de los actores sociales. Para Tatiana Sachs y Cyril Wolmark lo que ha ocurrido es que las autoridades públicas han organizado su propia retirada, fortalecieron la autonomía de las empresas para someterlas mejor a los mercados y a los requisitos de rentabilidad. Por lo anterior, en lugar de una reorganización del modelo social, las Ordenanzas de 2017 auguran principalmente su descomposición ${ }^{131}$.

Resulta en extremo complejo afirmar que se ha producido un cambio en el modelo francés de extensión de beneficios y en la ampliación. La autoridad administrativa sigue manteniendo la facultad para ello. Sin embargo, la arquitectura de los diferentes tipos de acuerdos y convenios a nivel de empresa y de rama se ve alterada, lo que sin duda afectará las extensiones y ampliaciones que la autoridad política (Ministerio del trabajo) decida en el futuro.

\section{EL ROL DEL LEGISLADOR EN LOS SISTEMAS INTERVENIDOS O REGLADOS}

Hemos estudiado dos mecanismos distintos de cobertura de la negociación colectiva, siguiendo la taxonomía de Gino Giugni de reconocimiento a los actores sociales del poder de dictar normas vinculantes para todos los sujetos incluidos en el ámbito del contrato (caso español), y la de un poder de extensión atribuido al Gobierno o a la autoridad administrativa (caso francés con la extensión y la ampliación).

${ }^{128}$ FAVENNEC-Héry, Françoise, Les PME dans les ordonnances Macron, en Droit social 1 (2018), p. 46.

${ }^{129}$ GÉA, Frédéric, Un changement de paradigme?, en Droit social 12 (2017), p. 997.

${ }^{130}$ JeAmmaud, cit. (n. 70), p. 36.

${ }^{131}$ SaChS, Tatiana - Wolmark, Cyril, Les réformes 2017: quels principes de composition?, en Droit social 12 (2017), p. 1008. 
Nuestro análisis se ha centrado en los procedimientos establecidos en cada una de estas modalidades, en orden a dilucidar, dentro de los modelos intervenidos o reglados, el rol y la importancia de la ley a diferencia de los modelos más autónomos, donde el sistema de relaciones laborales se basa en el rol protagónico de los actores sociales con relativa independencia del Estado, que se limita a establecer normas mínimas a fin de asegurar ciertos niveles de necesario cumplimiento y evitar excesos o abusos ${ }^{132}$. Lo anterior, con miras a visualizar sus diferencias, virtudes y defectos.

Cada modelo de negociación se desarrolla dentro de cierto contexto histórico, económico, político, ideológico y tecnológico, que le otorga una cierta identidad singular que conlleva que no haya dos sistemas idénticos, pero sí rasgos comunes entre ellos. En algunos predominará la autonomía, en otros la heteronomía. Algunos serán más centralizados y otros más descentralizados. Algunos estarán centrados en la cultura del conflicto, otros en la de cooperación ${ }^{133}$.

Tanto el modelo español como el francés son heterónomos ${ }^{134}$ y centralizados, aunque desde las reformas de Rajoy y Macron hay una clara tendencia descentralizadora.

Analizando lo ya expuesto de ambos sistemas, podemos decir que el rol de la ley puede adoptar distintas modalidades de regulación alternativas o complementarias:

i) Rol mínimo (regulación débil);

ii) Rol de fomento o promocional (regulación media);

iii) Rol protagónico (regulación fuerte);

iv) Rol prohibitivo (regulación restrictiva)

Estas modalidades, por otro lado, pueden comprender a los actores, los contenidos, la cobertura y los efectos de los instrumentos que se pacten o extiendan.

En el caso del modelo español y específicamente respecto del convenio colectivo estatutario, de eficacia erga omnes, observamos que la ley en materia de unidades de negociación deja una libertad importante a las partes sociales, configurándose una regulación mínima.

Respecto de las partes y su representatividad, el rol es bastante más interventor y de carácter protagónico, determinando la triple legitimación necesaria para convenir. Lo mismo puede observarse en cuanto al proce-

${ }^{132}$ ERMidA, cit. (n. 18), p. 6.

${ }^{133}$ Bronstein, Arturo S., Elementos estratégicos de la negociación colectiva: un panorama comparativo, en Revista Derecho del Trabajo 6 (2018), 19, p. 17.

${ }^{134}$ Véase por España Correa, cit. (n. 66), p. 35, y por Francia Lyon-Caen, cit. (n. 70), p. 10. 
dimiento de negociación, por medio de trámites estrictos y formalizados, articulándose a través de diferentes etapas.

En caso de fracaso o ruptura de las negociaciones, la ley autoriza a adoptar medidas de autotutela por medio de la huelga o un conflicto colectivo de intereses. Aquí el rol legislativo pasa a ser promocional o de fomento. Sin duda este será un elemento clave para el éxito de las negociaciones, ante la ausencia de obligatoriedad de contratar para los empleadores.

En el caso francés, tanto en el decreto de extensión como en el de ampliación (élargissement) el rol de la ley es de fomento y también protagónico.

En el caso de la extensión los requisitos del instrumento a extender, en lo relativo a las partes, su contenido y las cláusulas obligatorias, conlleva una regulación bastante protagónica. Lo mismo en cuanto al procedimiento y sus efectos.

En términos generales la extensión, desde el punto de vista de sus objetivos, forma parte también de una legislación de fomento o promoción, en este caso, la no concurrencia o competencia en base a malas condiciones de trabajo, impidiendo el dumping social dentro de una misma región o sector.

En materia de ampliación (élargissement) el rol de la ley es de fomento, ya que se trata de un instrumento conminatorio o promocional, en el sentido de dar una señal y una suerte de amenaza a los actores sociales de que se les aplicará una convención colectiva de otra región o sector si no llegan entre ellos a un acuerdo. Es un instrumento complementario a la extensión.

Una vez activada la ampliación, la ley cumple un rol protagónico respecto del procedimiento, de los requisitos y de sus efectos.

En ambos sistemas (español y francés) el rol de la ley es de fomento o promocional y de carácter protagónico.

Los roles extremos, a saber, mínimo y prohibitivo están más bien ausentes. El rol mínimo, como ya hemos dicho, es propio de los sistemas autónomos, como el uruguayo, y el rol prohibitivo es propio de los sistemas transgresores de la libertad sindical, por ejemplo, a través de materias prohibidas o prohibiciones de negociaciones multinivel. El sistema chileno es un buen ejemplo de esto último, con la prohibición de negociar las facultades de organizar, dirigir y administrar la empresa (art. 306 inciso cuarto del Código del Trabajo chileno) y con la exigencia de que el trabajador sólo puede estar regido por un contrato colectivo con el mismo empleador (art. 307 del Código del Trabajo chileno). En ambos casos, incluso si el empleador está de acuerdo, la ley lo prohíbe.

¿Cuál es la desventaja de estos sistemas (español y francés)? El sostén legislativo conlleva riesgos, ya que se incrementa notablemente la vulne- 
rabilidad del sistema frente a una eventual instrumentalización por parte de del legislador ${ }^{135}$.

Las reformas de Rajoy y Macron son un buen ejemplo de esta vulnerabilidad. En ambos casos se intenta descentralizar el modelo de negociación colectiva para ser más competitivos en el mercado global. En el caso español se alude a la rigidez de la legislación laboral, la que sería causante del alto desempleo. Es lo que Urrutikoetxea denuncia como una falacia, una estrategia discursiva y una retórica de la manipulación ${ }^{136}$.

En el caso francés las Ordenanzas Macron se hacen eco de la ideología economicista de la OCDE, que desaconseja las extensiones administrativas de los contratos colectivos ya que pueden atentar en contra de la libre competencia ${ }^{137}$.

Para varios autores los argumentos técnicos que avalan las reformas Rajoy y Macron no son objetivos, sino ideológicos ${ }^{138}$. Son recurrentes los ataques al derecho del trabajo aludiendo a su rigidez y a la necesidad de fomentar el empleo, aunque jamás las enmiendas legales hayan tenido esos efectos. Como señala Manuel Correa las causas de las crisis económicas son exógenas al propio mercado de trabajo ${ }^{139}$. Esta perspectiva economicista conlleva una cierta visión reduccionista de la compleja dimensión funcional de la negociación colectiva ${ }^{140}$.

Descentralizar la negociación colectiva propicia una disminución de su cobertura. Como ha señalado Arturo Bronstein, en los veinte países con mejor cobertura de negociación colectiva el nivel preferente de negociación es el ramal, de sector o de industria ${ }^{141}$.

En consecuencia los modelos intervenidos, por sofisticados que sean, tienen siempre como talón de Aquiles el consenso legislativo, donde una mayoría parlamentaria puede aprobar leyes y revertir los avances logrados.

¿Qué lecciones de política legislativa pueden extraerse de España y Francia para el derecho chileno? El caso de nuestro país es bastante particular, dado que su legislación es mayoritariamente prohibitiva y fuertemente protagónica, ya que arrincona la negociación colectiva dentro de la empresa.

Lo más complejo para un cambio en la situación actual es que un gobierno y una mayoría parlamentaria fortalecida tengan la convicción de

${ }^{135}$ Correa, cit. (n. 66), p. 36.

${ }^{136}$ URRUtikoetXeA, cit. (n. 65), pp. 19 ss.

${ }^{137}$ LyOn-CAEN, cit. (n. 70), p. 61.

${ }^{138}$ Véase Gamonal C., Sergio, Derecho laboral, economía y pseudociencia, en Derecho y Crítica Social 3 (2017), 1, pp. 1-44.

${ }^{139}$ Correa, cit. (n. 66), p. 50.

${ }^{140}$ Correa, cit. (n. 66), p. 50.

${ }^{141}$ Bronstein, cit. (n. 133), p. 30. 
que debemos marchar hacia un sistema ramal, para equilibrar las relaciones laborales y disminuir las grandes brechas de desigualdad provenientes de los bajos salarios. De momento una pretensión tal es un poco utópica. Hasta las fuerzas que se creen progresistas son temerosas del diálogo social y del empoderamiento de los trabajadores en nuestra realidad.

Existiendo esa convicción en un futuro próximo lejano, los ejemplos de España y Francia, antes de sus reformas descentralizadoras podrían ser una línea de referencia a seguir ${ }^{142}$. En este caso, debiera primero desarrollarse un sistema de negociación de los actores más representativos, para luego complementarlo con un sistema de extensión o ampliación.

El rol de la legislación debiera mutar de uno prohibitivo a otro de fomento o promocional así como a un rol protagónico respetuoso de la libertad sindical. En este contexto imaginario, el legislador debería regular a los actores, los contenidos, la cobertura y los efectos de los instrumentos de cobertura ramal. Estimamos que un período transitorio de prueba y de conformación y organización de los respectivos actores sociales, sería esencial para el éxito del modelo.

Por último, otro elemento clave para el éxito es la consagración de un sistema de autotutela efectivo. Es decir, al igual que en el caso español, frente al fracaso o ruptura de las negociaciones, los sindicatos de trabajadores debieran poder recurrir a la huelga u otras medidas de presión colectivas.

\section{CONCLUSIONES}

En este trabajo hemos estudiado los casos español y francés, de negociación ramal el primero y de mecanismos de extensión el segundo. Ambos son buenos ejemplos de la modalidad 1 y 2 de la clásica taxonomía de Gino Giugni, sobre modelos de negociación colectiva.

Nuestro objetivo se ha centrado en estudiar un ejemplo de cada modalidad y ver el rol del legislador en los procedimientos establecidos en cada una.

Ambos son modelos intervenidos o reglados, con protagonismo de la ley a diferencia de los modelos más autónomos, donde el sistema de relaciones laborales se basa en el rol protagónico de los actores sociales con relativa independencia del Estado.

Ambos sistemas han sido exitosos en obtener una alta cobertura de la negociación, y el rol de la ley ha sido preferentemente de protagonismo respetuoso de la libertad sindical y de fomento o promoción.

${ }^{142}$ Otra alternativa sería adoptar la línea de los consejos de salarios de Uruguay. Véase Loustaunau, Nelson E., Consejos de Salarios (Montevideo, Fundación de Cultura Universitaria, 2010). 
Con todo, los sistemas intervenidos, con protagonismo del legislador adolecen de un defecto, a saber, cuando el consenso político desconoce y ataca el modelo negociador. Sobre todo buscando su descentralización a nivel de empresa.

Ha sido el caso de las recientes reformas de Rajoy y Macron en los países estudiados.

De llegar a implementarse un sistema negociador de mayor cobertura en Chile, sería necesario primero el consenso legislativo para elaborar leyes que pudieran basarse en los sistemas estudiados. Obviamente esta opción no es obligatoria, podrían basarse en otro modelo, por ejemplo, en los consejos de salarios de Uruguay.

Pero de seguirse el caso Español y Francés, el rol del legislador debiera ser de fomento y protagónico, teniendo en cuenta eso sí el respeto irrestricto a la libertad sindical.

La nueva legislación debería regular a los actores, los contenidos, la cobertura y los efectos de los contratos de cobertura ramal. Para la implementación de un sistema tal, sería esencial un período transitorio de prueba y de conformación y organización de los respectivos actores sociales.

Finalmente, otro elemento clave para el éxito es la consagración de un sistema de autotutela efectivo, en otras palabras, que en caso de fracaso o ruptura de las negociaciones, los sindicatos de trabajadores debieran poder recurrir a la huelga u otras medidas de presión de presión.

\section{BiBLIOGRAFÍA}

Adam, Patrice, L'accord de branche, en Droit social 12 (2017).

Auzero, Gilles, Conventions d'entreprise et conventions de branche, en Droit social 12 (2017).

Auzero, Gilles - Baugard, Dirk - Dockès, Emmanuel, Droit du travail (Paris, Dalloz, 2018).

Baylos Grau, Antonio, ¿Para qué sirve un sindicato? (Madrid, Catarata, 2012).

Baylos Grau, Antonio, El Sentido General de la Reforma: La Ruptura de los Equilibrios Organizativos y Colectivos y la Exaltación del Poder Privado del Empresario, en Revista de Derecho Social 57 (2012).

Baylos Grau, Antonio, Derecho del Trabajo: modelo para armar (Madrid, Trotta, 1991). Bronstein, Arturo S., Elementos estratégicos de la negociación colectiva: un panorama comparativo, en Revista Derecho del Trabajo 6 (2018), 19.

Canut, Florence - Verkindt, Pierre-Yves, Négocier sous contrainte. Un nouveau visage de la négociation collective en France?, en Mélanges en l'honneur du Professeur François Gaudu, Droit du travail, Emploi, Entreprise (Collection Bibliothèque de I'IRJS - André Tunc, Paris, IRJS Editions, 2014). 
Casanova, Javier Alexandre, Negociación Colectiva y Poder Sindical en Europa, (Universidad Autónoma de Barcelona, 2013), disponible [en línea]: https://www. researchgate.net/publication/237201862_NEGOCIACION_COLECTIVA_Y_ PODER_SINDICAL_EN_EUROPA.

Correa Carrasco, Manuel, La Ordenación de la Estructura de la Negociación Colectiva tras las Recientes Reformas Laborales, en Revista de Derecho Social 59 (2012).

Couturier, Gérard, Traité de droit du travail, 2/ Les relations collectives du travail (París, Presses Universitaires de Paris, 2001).

Cruz Villalón, Jesús, El Descuelgue de Condiciones Pactadas en Convenio Colectivo tras la Reforma de 2012, en Revista de Derecho Social 57 (2012).

D'Antona, Massimo, I mutamenti del diritto del lavoro ed il problema della subordinazione, en Caruso, Bruno - Sciarra, Silvana, OPERE (Milán, Giuffrè, 2000), III.

Durán, Gonzalo, Negociación Colectiva por Sector Económico, Productividad, empleo y desigualdad. Un análisis comparado (Santiago, Fundación Sol, 2015), disponible [en línea]: https://izajolp.springeropen.com/articles/10.1186/s40173-016-0061-1.

Ermida Uriarte, Óscar, Las Relaciones del Trabajo en América Latina (Lima, Crítica \& Comunicación, Oficina Regional de la OIT para América Latina y el Caribe, 1991).

Ermida Uriarte, Óscar, Introducción, en: Cuarenta Estudios sobre la Nueva Legislación Laboral Uruguaya, XXXV aniversario del Grupo de los Miércoles (Montevideo, Fundación de Cultura Universitaria, 2010).

Favennec-Héry, Françoise, Les PME dans les ordonnances Macron, en Droit social 1 (2018).

Fita Ortega, Fernando, Los modelos de negociación colectiva en la Unión Europea, en Rojas, Irene, La Negociación Colectiva en Chile (Santiago, CENTRASS, Librotecnia, 2014).

Gamonal Contreras, Sergio, Derecho Colectivo del Trabajo (2a edición revisada y actualizada, Santiago, Abeledo Perrot, 2011).

Gamonal Contreras, Sergio, Las dos almas del derecho del trabajo, en Revista de Derecho Laboral y Seguridad Social 1 (2013), 1.

Géa, Frédéric, Un changement de paradigme?, en Droit social 12 (2017).

Giugni, Gino, Diritto Sindacale (actualizado por Lauralba Bellardi, Pietro Curzio y Vito Leccese, Bari, Cacucci, 2015).

Giugni, Gino, La extensión de los contratos colectivos, en Ermida, Óscar - Ojeda, Antonio, La Negociación Colectiva en América Latina (Madrid, Trotta, 1993).

Giugni, Gino, Lavoro, legge, contratti (Bolonia, Il Mulino, 1989).

Jeammaud, Antoine, La «Reforma Macron» del Código del Trabajo francés, en Revista Derecho del Trabajo 6 (2018), 18.

Kerckhofs, Peter, Extension of collective agreements in the EU (Eurofound, 2011), disponible [en línea]: https://www.eurofound.europa.eu/publications/customisedreport/2011/industrial-relations/extension-of-collective-bargaining-agreementsin-the-eu-background-paper.

López, Julia, Elementos de Definición del Modelo de Relaciones Laborales por las Normas de la OIT y Comunitarias: la Desestabilización por la Reforma Laboral (2012), en Revista de Derecho Social 57, (2012).

Loustaunau, Nelson E., Consejos de Salarios (Montevideo, Fundación de Cultura Universitaria, 2010).

Lyon-Caen, Antoine, Ordonnances Macron, Commentaires pratiques et nouvelles dispositions du code du travail (Dalloz, Paris, 2018). 
Macchiavello Contreras, Guido, Derecho Colectivo del Trabajo (Santiago, Editorial Jurídica de Chile, 1989).

Martínez-Matute, Marta, La Cobertura de la Negociación Colectiva en España: Una nueva propuesta de medición, en Revista de Economía Laboral 13 (2016), 2.

Mazeaud, Antoine, Droit du Travail (París, Montchrestien, 2004).

Monereo Pérez, José Luis - Molina Navarrete, Cristóbal - Moreno Vida, María Nieves, Manual de Derecho Sindical (12a edición, Granada, Comares, 2017).

Montoya Melgar, Alfredo, Derecho del Trabajo (38a edición, Madrid, Tecnos, 2017).

Palomeque López, Manoel-Carlos, Derecho Sindical (3a edición revisada por Djamil Tony Kahale Carrillo, Madrid, Centro de Estudios Financieros, 2016).

Sachs, Tatiana - Wolmark, Cyril, Les réformes 2017 : quels principes de composition?, en Droit social 12 (2017).

Sala Franco, Tomás, Derecho Sindical (2a edición, Valencia, Tirant lo Blanch, 2017).

Salido Banús, José Luis, Manual de Derecho Sindical (4a edición, Barcelona, Atelier, 2017).

Supiot, Alain, Critica del Derecho del Trabajo (Madrid, Ministerio del Trabajo y Asuntos Sociales, 1996).

Urrutikoetxea Barrutia, Mikel, El Preámbulo del RD Ley 3/2012, o las Retóricas de la Manipulación, en Revista de Derecho Social 57 (2012).

Vachet, Gérard, Le principe de faveur dans les rapports entre sources de droit, en Teyssié, Bernard (dir.), Les Principes Dans la Jurisprudence de la Chambre Sociale de la Cour de Cassation (París, Dalloz, 2008).

Verdier, Jean-Maurice - Coeuret, Alain - Souriac, Marie-Armelle, Droit du Travail (Rapports Collectifs, París, Dalloz, 2005), I.

Vicente Palacio, Arántzazu, Manual de Derecho Sindical (4a edición, Barcelona, Atelier, 2017). 